\title{
Best practices and opportunity areas for the intelligent management of virtual teams
}

\author{
Garcia-Guardado Enrique $^{a^{*}}$ and Mendoza-Gomez Joel ${ }^{a}$
}

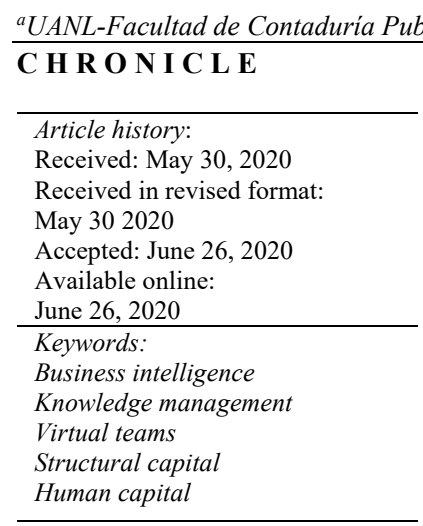

and Administracion. Nuevo Leon, Mexico

\section{A B S T R A C T}

Current organizations need to create advantages by measuring and developing intangible resources. Business intelligence and knowledge management help to achieve it. On the other hand, virtual teams have problems that make the regularization of their work processes and their social interaction methods difficult and restrict the team members to unfold efficiently. Knowledge management purposes skills from structural capital and human capital and it is believed to solve these types of problems in virtual teams. This research has the objective to identify the best practices and opportunity areas for the intelligent management of virtual teams by showing practical suggestions in the discussion built with the inferential statistics testing of five hypotheses. The results indicate that three hypotheses were accepted while two were rejected.

(C) 2020 by the authors; licensee Growing Science, Canada

\section{Introduction}

Current market and technology circumstances force organizations of any background to seek competitive advantages with intangible assets. These types of assets promote human resources development by improving the use of information that allows them to gain knowledge and apply it to innovate. The substance of this topic was studied in past research, for example, Ahumada and Perusquia (2016) proposed strategies based on Business Intelligence to achieve development in favor of innovation. However, these works analyze models missing in their scope to observe individuals that go through a working process with interactions that require socialization with other people. This paper proposes a model to develop trust in virtual team members. Its results analysis exposed efficient methods and opportunity areas in virtual teams considering intangible assets management, commonly known as Knowledge Management. This explanatory research not only contributes to theoretical proposals about Knowledge Management and virtual teams but also includes applicable recommendations to any managerial level that is in care of them. Also, literature concerning virtual teams is the extent, hence here are highlighted the most important elements to manage virtual teams with Business Intelligence. For these motives, it is considered that this research covers theoretical and practical gaps about Business Intelligence, Knowledge Management, and Virtual teams by exhibiting, the best practices and opportunity areas for the intelligent management of virtual teams.

\section{Literature review}

\subsection{Business intelligence and Knowledge Management}

Business Intelligence is the use of methodologies proposed by Knowledge Management addressed to enterprises. This Management branch is defined as the use of a process in which abstracts (like new ideas), and intangible (like knowledge level of an employee) are transformed in concrete and applicable (like software and manuals). These processes, not only have organized data, but also allow enterprises to measure, analyze, and change, create innovations, and new knowledge (Pasher \& 
Ronen, 2011). Related to this, Knowledge Management is composed of three elements that manage the processes of organizations, labor skills, and the relationship of organizations with their external factors. These three elements are recognized by Knowledge Management as 1) Structural Capital, 2) Human Capital, and 3) Relational Capital (Pasher \& Ronen, 2011; Lanzas 2018). Structural Capital are the processes of organizations to improve their resources network to make them more trustful, and valuable during the working process of employees through acquisition, development, integration, strengthening, and creation of new working networks applied as strategies (García, Parra, \& Molina, 2018). Human Capital oversees measuring people's cognitions. These elements create value by generating new social relationships with the improvement of the interaction among individuals. The value is generated when enterprises develop a system in which solidarity, collective vision, and mutual understanding (Boon et al., 2018; García et al., 2018). Relational Capital is the creation of interactions outside the organization. This type of capital gives importance to communication between different enterprises. When there is an alliance among suppliers, homonyms, and clients there is a development of solidarity, knowledge is shared, there are goals alignments, and risks and rewards are shared (Aaltonen \& Turkulainen, 2018).

\subsection{Intelligent management of Virtual Teams}

Enterprises rather work with virtual teams for their possibility to reduce time and costs. Virtual teams are groups of two or more interdependent people that must interact with information and communication technologies due to their geographical separation (Gibson et al., 2014; Martins et al., 2004; Powell et al., 2004). These teams are exposed to situations in which their working process involves the use of communication tools, their relationship with others, and shared goals. Due to the complexity of technology, the team's thoughts, and work; it is needed a favorable system that avoids or solve conflicts, creativity to solve problems is fostered, and reduce individualism (Kirkman \& Mathieu, 2005; Marlow et al., 2017). As mentioned before, Knowledge Management allows the creation of processes focused on benefitting from structural capital, human capital, and relational capital of an organization. Therefore, virtual teams require this branch of Management to do work more efficiently, avoid or solve problems related to the interactions of the virtual team members (Ahumada \& Perusquia, 2016; Lanzas, 2018; Maznevski \& Chudoba, 2000). This work uses the concept of intelligent management of virtual teams to the application of Knowledge Management in a virtual team's management.

\subsection{Trust in virtual environments: Developer of cohesion and certainty}

In enterprises, virtual teams are formed to fulfill projects that need specialists. It is common that in these projects interactions among virtual team members are reduced, even in some of the occasions the team members only receive their role instructions and they never meet the rest of the team (Orhan, 2014). Contrary to the theory of Knowledge Management, this individualist working procedure affects the performance of virtual teams, and with it, the quality of their product. Because socialization and information networks are nonexistent, and this reduces knowledge and innovation (Gilson et al., 2015). For that reason, enterprises must apply the elements proposed by Knowledge Management that lower social distancing and uncertainty of virtual team members. Trust is an effective and rational element that develops individually, but it comes from the interaction from others. And, it can cover group levels. In a labor environment, trust unfolds from collaboration, beliefs, and compromises, causing the removal of individual interests while people work together (Germain \& McGuire, 2014; Kanaris, 2015). Regarding trust in virtual environments, previous work proved its existence and its possible effect on virtual team members, but there is a need to attend studies related to methodologies, strategies, or processes of virtual teams to develop an environment in which cohesion and certainty are produced by trust (García \& Mendoza, 2015; Zornoza et al., 2009). This work observes elements related to structural capital and human capital because the virtual team members observed were not related to external organizations.

\subsection{Structural capital skills: Technical communication, performance feedback, and timely information of process}

Technical communication, performance feedback, and timely information of process are considered structural capital skills due to within this research are measured as skills used to acquire, improve, or integrate the working strategies of virtual team members. People that work in virtual environments need to be trained to use effectively the communication tools provided by the organization in which they work. The training must contribute to determining objectives, conditions, individual, and group roles (Berridi et al., 2015). This skill is named as technical communication. Performance feedback is applied to adjust and create information in which the actions of the virtual team members are modified to transform the feedback in data that can be used for future projects (Son \& Kim, 2015). Timely information of process is the measurement of the frequency in which the virtual team members share their information. The frequency must by synched so the team members can be updated about the status of their team-mates, change of plans, and resources, and vital information data are shared on time to continue with their working process without interruption (Huang, 2016).

\subsection{Human capital skills: Dialogic learning and intercultural competence}

Dialogic learning and intercultural competence are considered human capital skills that ought to their capacity to measure learning, acquire knowledge, create knowledge, and contribute ideas. Dialogic learning is the creation of knowledge from the interaction of virtual team members. The interactions are rational conversations in which ideas are shared to contribute to the whole team (Berridi et al., 2015). Intercultural competence is giving the capacity to virtual team members to benefit from cultural differences and to improve their interactions by contrasting behavioral differences and transform them in advantages that give value to the team (Huey et al., 2014). 


\subsection{Research objective}

Trust in virtual environments is an essential skill for the intelligent management of virtual teams, thus it is considered as the dependent variable of the phenomenon. The literature review identified competencies to develop trust in virtual environments which are the independent variables of the model. The independent variables technical communication, performance feedback, timely information of process, are variables that are considered structural capital skills. The independent variables dialogic learning and intercultural competence are considered human capital skills. With the topics here exposed in the literature review the main objective of this research is to solve the research questions: Which are the best practices for intelligent management of virtual teams? And Which are the opportunity areas for intelligent management of virtual teams?

\subsection{Hypothesis development}

Intelligent management of virtual teams requires a straight functionality and simplicity of communication tools to synch the rationale of virtual team members (Lam, 2016). Technical communication gives people skills to transform communication tools in a balanced and cooperative environment, so obstacles become in a base of transmission with a direction to generate trust (Mirra et al., 2018). From these ideas is derived the first hypothesis:

$\mathrm{H}_{1}$ : Technical communication has a positive effect on virtual team members' trust.

Virtual teams need a corrective function that make team member conscient about the importance of their individual effort in the team. Performance feedback gives a sense of achievement to the individual decisions of team members and managers (Steelman et al., 2004). Also, it creates a self-assessment mentality during the working process. Therefore, it is considered that performance feedback generates trust by re-stating that the whole team is working effectively and eliminates the need to observe each other (Tarakci et al., 2018). Thus, the second hypothesis is:

$\mathrm{H}_{2}$ : Performance feedback has a positive effect on virtual team members' trust.

In a virtual environment, the quantity of shared information must have a structure, because the overload of information can affect the quality of the working and decision-making processes. On the other hand, lack of information can complicate the reaction to emergent situations (Rusman et al., 2009). Timely information of process is in charge of structuring the information and accept it according to the situation, this avoids misunderstandings among team members and prepare them for future complications. Therefore, with better delivery times and frequencies of information, confusion, and uncertainty is eliminated, as a result, trust can be generated. (Kaur, 2018). With these ideas the third hypothesis is:

$H_{3}$ : Timely information of process has a positive effect on virtual team members' trust.

Following the proposals of Takahashi et al. (2014), usually on remote work people only send their working progress. In a virtual team with intelligent management, there are relationships created from dialogue, all the team members share their knowledge, and collectivity exists. Dialogic learning is a method in which virtual team members give opinions and are listening. Their opinions solve problems or create innovation. A rational conversation gives purpose to their opinions, from a rational collectivity creates a relational collectivity, with that, generates trust. From this perspective the fourth hypothesis is:

$\mathrm{H}_{4}$ : Dialogic learning has a positive effect on virtual team members' trust.

Cultural differences between virtual teams can be social or labor. These differences affect the whole team by conflicting the credibility of information, aptitudes, and behavior towards team members. For this intercultural competence must be integrated into virtual teams' intelligent management. Intercultural competence eliminates understanding gaps and benefits of multiculturality of a team to develop advantages through creativity, different perspectives. All this gives virtual team members an emotional and labor stability focused on the generation of trust by making the team more cohesive (Arasaratnam, 2016; Vegh \& Nguyen, 2019). Proposing the fourth hypothesis:

$H_{5}$ : Intercultural competence has a positive effect on virtual team members' trust.

Following the above mentioned it was made an inferential analysis to prove the hypothesis of the model (see Fig. 1):

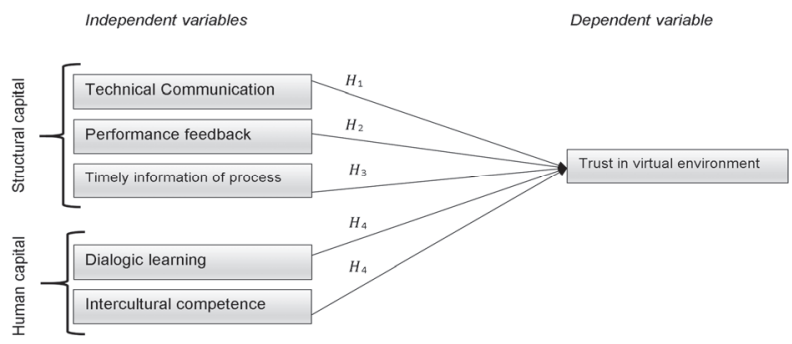

Fig. 1. Proposed graphic model. Note: own elaboration 


\section{Methodology}

\subsection{Research design}

This quantitative transactional research has an explanatory scope to understand the causes of the generation of trust in a virtual environment among virtual team members. The actions of the participants were not intervened; therefore, this research is considered nonexperimental (Blundell \& Costa Dias, 2005; Creswell \& Creswell, 2017). To do this, five independent variables and a dependent variable were observed to test the hypothesis with multiple linear regression. This research design was possible to measure the importance, proximity, and weight of the variables within the model with a unidirectional relation. After data analysis, is presented a discussion. (Kaplan, 2004; Cruz, 2017).

\subsection{Instrument design}

The variables of the model were operationalized by identifying theoretical research that defined the variables with a similar scope to the present work. But the referenced works were made in different backgrounds; for example, variables dedicated to observing face-to-face teams. For this motive, the conceptualizations and items from other authors were adapted to study specifically for proper data recollection dedicated to the background of a virtual team. After the operationalization of the variables, it was developed an instrument of 36 closed-ended questions with a Likert scale from 1 to 7 to test the model's hypothesis (Rositas, 2014). To ensure that participants were part of a virtual team, the instrument contained a second section with 10 open-ended questions (Oviedo \& Arias, 2005; Cervantes, 2005).

\subsection{Sample characteristics}

A convenience non-probabilistic sampling method was used to gather data from 102 virtual team members of Monterrey city at the northeast of Mexico. The enterprises are dedicated to design computing systems. The characteristics to consider the participants as virtual team members were (Tongco, 2007):

- To work in a group of two or more people

- The group must be labeled

- The group must have at least six months working together

- To have interdependent tasks

- To have the obligation to use Information and Communication Technologies to communicate and develop their projects.

\subsection{Field work}

The instrument was applied with Google forms. The platform allowed to distribute the instrument and to access it through email, so any participant could answer the questioner with their personal computers or mobile devices. After exporting data to an Excel spreadsheet, it was introduced to SPSS to analyze it.

\subsection{Statistical analysis methods}

Before running a multiple linear regression, closed-ended questions were analyzed with parametric methods required to confirm that data had validity, was precise, and fulfills all assumptions (de la Garza et al., 2012). All statistical tests were made with a $95 \%$ probability as required by social sciences (de la Garza et al., 2012). Reliability was tested with Cronbach's Alpha value for each of the variables. The scale to accept reliability was proposed by Gliem and Gliem (2003) in which establishes that $\alpha \geq 0.9$ reliability is excellent, $\alpha \geq 0.8$ reliability is good, $\alpha \geq 0.6$ reliability is questionable, $\alpha<0.5$ reliability is poor, and reliability is unacceptable. To reject the presence of multicollinearity between independent variables the Variance Inflation Factor (VIF) was measured. After that, the Pearson correlation coefficient of the variables was calculated to accept model's linearity. The normality of the sample was tested with Kolmogorov-Smirnov-Lilliefors' test of the dependent variable. Homoscedasticity was observed with the consistency of data in the standardized residuals. To end with all assumptions model's autocorrelation was tested with Durbin-Watson's coefficient (Cazalla, et al., 1999; de la Garza, et al., 2012). After testing all assumptions, an inferential statistical analysis was made by observing the determination coefficient, Fischer's $\mathrm{F}$ test, and nonstandardized coefficients of the variables were used to test hypotheses (de la Garza et al., 2012).

\subsection{Reliability test}

Table 1 shows the results of reliability test in descendent order according to their Cronbach's alpha value. In the results, it can be observed that trust in virtual environments had the highest Cronbach's alpha value $(\alpha=.781)$. In addition, the variable with the lowest Cronbach's alpha value was technical communication $(\alpha=.626)$. In general, all variables were above the unacceptable range. With these results, reliability was accepted to continue with the following assumptions.

\subsection{Multicolinearity test}

Technical communication, intercultural competence, timely information of process, and performance feedback had a VIF $<2$. Related to these results, dialogic learning had the highest VIF value but still is in range to reject multicollinearity (de la Garza, et al., 2012). These results are in Table 1. 


\subsection{Linearity test}

The linearity test was accepted when all variables had a $\mathrm{p}<.05$ with a reliability of $95 \%$. Table 1 shows the results of Pearson's coefficient correlation

\subsection{Normality test}

Kolmogorov-Smirnov-Lilliefors' test results allowed to accept the normality of the sample with a p $>.200$. Table 1 shows the results of this test.

\subsection{Homoscedasticity test}

Variance homogeneity was accepted by observing that the probability standardized residuals show consistency in their direction towards the top right end of the graphic (de la Garza et al., 2012). Fig. 2 shows the results.

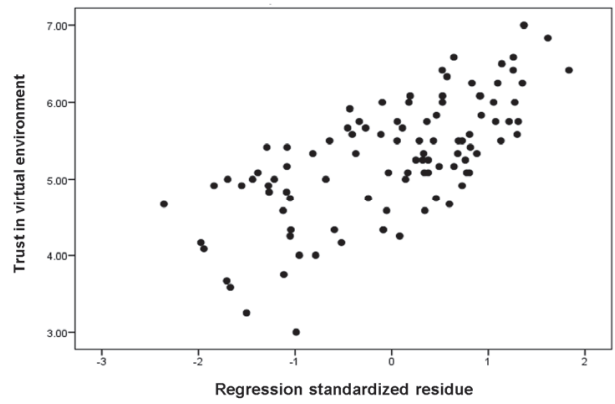

Fig. 2. Homoscedasticity test Note: Own elaboration, data generated from SPSS

\subsection{Autocorrelation test}

Durbin-Watson's coefficient was $d=1.55$. This allows accepting the alternative hypothesis. This autocorrelation is rejected from the model (de la Garza et al., 2012). The results are shown in Table 1.

\subsection{Assumptions review}

All assumptions required by multiple linear regression were fulfilled to continue with the inferential statistical analysis. Here is Table 1 with the results of the reliability test, multicollinearity test, and linearity test:

Table 1

Assumptions results review

\begin{tabular}{lllll}
\hline Variable & $\begin{array}{l}\text { Cronbach's } \\
\text { alpha }\end{array}$ & VIF & $\begin{array}{l}\text { Pearson's } \\
\text { correlation coefficient }\end{array}$ & $\begin{array}{l}\text { Number of ítems } \\
\text { by variable }\end{array}$ \\
\hline Trust in virtual environments & .781 & Constant & 1.000 & .539 \\
Technical communication & .626 & 1.308 & .272 & .000 \\
Intercultural competence & .738 & 1.356 & .572 & .003 \\
Timely information of process & .660 & 1.821 & .529 & .000 \\
Performance feedback & .752 & 1.865 & .572 & .000 \\
Dialogic learning & .772 & 2.276 & .000 & 7 \\
\hline
\end{tabular}

Note: own elaboration, data generated from SPSS with $95 \%$ reliability.

\section{Results}

\subsection{Statistical inferential analysis}

The determination coefficient had a value of .523 . Fischer's test result was $F=21.020$, giving the model a significance of $\mathrm{p}<.000$ with a $95 \%$ reliability. Table 2 shows the results of the statistical inferential analysis.

Table 2

Model's test

\begin{tabular}{ccc}
\hline $\boldsymbol{R}^{\mathbf{2}}$ & $\mathbf{F}$ & Significance \\
\hline .523 & 21.020 & .000 \\
\hline
\end{tabular}

Note: Own elaboration data generated from SPSS with 95\% reliability

The results of the standardized coefficient of independent variables show that the most important variable of the model is technical communication with $\beta=.391$. On the other hand, intercultural competence had a negative weight within the model with a value of $\beta=-0.90$. About significance, technical communication, performance feedback and timely information of process have a value of $\mathrm{p}<.05$, with these results their hypothesis in the model was accepted. But dialogic learning and intercultural competence had a value of $\mathrm{p}>.05$ rejecting their hypothesis in the model. Table 3 shows the results of the standardized coefficients of the independent variables, their $t$ value, p-value, and hypothesis test: 
Table 3

Standardized coefficients of independent variables and hypothesis test

\begin{tabular}{|c|c|c|c|c|}
\hline Hypothesis & $\beta$ & $t$ & Sig. & Test result \\
\hline$H^{1}$ Technical communication $\stackrel{(+)}{\rightarrow}$ Trust in virtual environments & 391 & 4.318 & .000 & $H^{1}$ Accepted \\
\hline$H^{2}$ Performance feedback $\stackrel{(+)}{\rightarrow}$ Trust in virtual environments & .266 & 2.472 & .015 & $H^{2}$ Accepted \\
\hline$H^{3}$ Timely information of process $\stackrel{(+)}{\rightarrow}$ Trust in virtual environments & .216 & 2.720 & .008 & $H^{3}$ Accepted \\
\hline$H^{4}$ Aprendizaje dialógico Dialogic learning $\stackrel{(+)}{\rightarrow}$ Trust in virtual environments & .168 & 1.312 & .193 & $H^{4}$ Rejected \\
\hline$H^{5}$ Intercultural competence $\stackrel{(+)}{\rightarrow}$ Trust in virtual environments & -.090 & -.840 & .403 & $H^{5}$ Rejected \\
\hline
\end{tabular}

Note: Own elaboration, data elaborated from SPSS with reliability of $95 \%$

\section{Discussion}

\subsection{Best practices for intelligent management of virtual teams}

Virtual team members develop their activities favorable for capital structural, as technical communication, performance feedback, timely information of process to generate trust in virtual environments. The value and model's significance show that when these three skills are present, they can generate $52 \%$ of trust in virtual environments.

\subsection{Technical communication recommendations}

Strategies related to technical communication are considered a healthy practice for virtual teams. This skill is responsible for generating $39 \%$ in the benefit of trust among team members in a virtual environment. To do this, virtual team members must be trained to use Information and Communication Technologies as working tools, mainly, to adapt them to be used in a collaborative distanced environment (Lam, 2016). Intelligent management of virtual teams allows their members to communicate in optimal conditions to report their work. Also, there is an agreement that team members must share information in regular meetings. For example, the exchange of information must occur in specific meetings to report their working progress. Nowadays, there is software that integrates solutions that allow the management of meetings, share files, and applications; to create a network of information among virtual team members. Therefore, people that use this type of service are doing one of the best practices to manage a virtual team. (Mirra et al., 2018).

\subsection{Performance feedback recommendations}

Virtual team members have good practices when their work has performance feedback. This skill is responsible for generating $26 \%$ of the trust in virtual environments. Virtual team members must develop a positive feedback system in order to create a conscience of their work with constructive commentaries (Steelman et al., 2004). A system with these characteristics has virtual team members that are emotionally intelligent to do commentaries based on the creation of an expectative in the behavior of others. This is achieved by structuring the individual tasks of each member. Also, the commentaries made to other team members do not need formalization but politeness to create a sense of responsibility for the general performance of the team. With a system like this, each virtual team member accepts their role within the team, and it is an alternative to measure their individual input to the whole team (Tarakci et al., 2018).

\subsection{Timely information of process recommendations}

Similarly, the actions that foster timely information of process in a virtual team are considered as good practices. This variable has the potential to generate $21 \%$ of trust in virtual environments. Timely information of process makes that virtual team members contribute to their output with anticipation. It is a skill that updates the working status of all team members, keeps current the individual tasks, and makes the team available to solve emergencies, therefore, the final product without delays (Rusman et al., 2009). Intelligent management of timely information of process is present when the virtual team manages the overload of information with project management tools (Kaur, 2018). There are tools that allow using virtual whiteboards, in which everyone in the team can browse their to-do list. Their lists can include data as, who is responsible for each task, to assign delivery dates, and compare schedules. There are more complex tools like collaborative project management software but they add specific functions for developing software. On the other hand, there are more simple methods in which every virtual team member shares a document in cloud storage in order to edit the information to create a network of information. Nowadays these types of tools are available for mobile devices and personal computers that allow the constant synchronization of the information (Ramos et al., 2019).

\subsection{Opportunity areas for virtual teams' management}

After the analysis, it was detected that there are opportunity areas for virtual team management. Dialogic learning and intercultural competence must be developed to achieve the intelligent management of virtual teams. The statistical assumptions show that these two variables have the possibility to exist within the model, but the inferential analysis of the model shows that they need to be put into practice to generate more trust in a virtual team. Also, it is important to note that the variables that were not significant within the model are part of the human capital. 


\subsection{Dialogic learning recommendations}

Dialogic learning is considered an opportunity area. The results show that this variable has the possibility to contribute to the generation of trust in virtual environments by $17 \%$. According to the literature review, this skill is put into practice when virtual teams standardize having constant meetings to discuss and solve individual or group problems related to their tasks during as long as their project takes (Takahashi et al., 2014). Also, Knowledge management proposes the use of communities of practice. The main function of communities of practice is to collaborate and innovate through socializing practices as dialogue. Communities of practice can take place with people that have interests in common. In the case of virtual team members, they must have the interest to deliver a final product. To have communities of practice meetings allow to take advantage of the time to share experiences and uncertainty about their job. With this method, there is inspiration in others to promote new ideas and solve problems. For communities of practice to work well, there must be a balance between formal and casual conversations. Casual conversations make easier for people to express themselves and free of thinking. While formal conversations establish limits to focus on giving solutions and to make a quality job. (Castaneda et al., 2018).

\subsection{Intercultural competence}

Missing actions to improve intercultural competence is considered an area of opportunity that must be covered. Although in this research it had a negative relation the statistical assumptions show that it has a $60 \%$ chance to generate trust in virtual environments. To improve intercultural competence, virtual team members must be open to accepting teammates with another type of knowledge and personality. The variation of contributions coming from different backgrounds helps to learn from others (Arasaratnam, 2016; Rezazadeh \& Molaei, 2018). Virtual team members must behave politely and focus on the skills, knowledge, and attitudes that differ from one person to another while working. It becomes a responsibility to virtual team managers to develop a model where their progress is identified by the adjustments that team members must do when they interact among different cultures. For this, an initial perception of the team members must be measured, then to intervene to create sensibility among the virtual team and to observe them during all the stages of their project until an intercultural competence of the whole team is achieved (Vegh \& Nguyen, 2019).

\section{Conclusions}

The main objective of this research was achieved when better practices and opportunity areas for the intelligent management of virtual teams were identified. It was important to meet the skills that are used by the intelligent management of virtual teams but, it is also important to standardize a process to develop them regularly in different types of projects in which virtual team members are essential. The literature review of this study can be applied in other research related to Knowledge Management and measure other key elements related to structural, relational, and human capital, and all types of teams that have the intention to act more intelligent to generate competitive advantages from human resources in organizations. Also, this study can be used to develop a complete system where all strategies become efficient and make intelligent virtual teams.

\section{References}

Aaltonen, K., \& Turkulainen, V. (2018). Creating relational capital through socialization in project alliances. International Journal of Operations \& Production Management, 38(6), 1387-1421.

Ahumada Tello, E., \& Perusquia Velasco, J. M. A. (2016). Inteligencia de negocios: estrategia para el desarrollo de competitividad en empresas de base tecnológica. Contaduría \& Administración, 61(1), 127-158.

Arasaratnam, L. A. (2016). Intercultural Competence. Oxford Research Encyclopedia of Communication.

Berridi Ramírez, R., Martínez Guerrero, J. I., \& García Cabrero, B. (2015). Validación de una escala de interacción en contextos virtuales de aprendizaje. Revista electrónica de investigación educativa, 17(1), 116-129.

Blundell, R., \& Costa Dias, M. (2005). Evaluation Methods for Non-Experimental Data. Fiscal Studies, 21(4), 427-468.

Boon, C., Eckardt, R., Lepak, D. P., \& Boselie, P. (2018). Integrating strategic human capital and strategic human resource management. The International Journal of Human Resource Management, 29(1), 34-67.

Castaneda, D. I., Manrique, L. F., \& Cuellar, S. (2018). Is organizational learning being absorbed by knowledge management? A systematic review. Journal of Knowledge Management, 22(2), 299-325.

Cazalla, O., Sebastián, E., Cultrone, G., Nechar, M., \& Bagur, M. G. (1999). Three-way ANOVA interaction analysis and ultrasonic testing to evaluate air lime mortars used in cultural heritage conservation projects. Cement and Concrete Research, 29(11), 17491752.

Cervantes, V. H. (2005). Interpretaciones del coeficiente Alpha de Cronbach. Avances en medición, 3(1), 9-28.

Creswell, J. W., \& Creswell, J. D. (2017). Research design: Qualitative, quantitative, and mixed methods approaches. Sage publications.

Cruz, L. (2017). Modelo de regresión lineal múltiple con datos transversales. Econometría aplicada usando stata 13, 25-3. Cali: Sello Editorial Javeriano.

De la Garza, J., Morales, B., Gónzalez, B. (2012). Análisis estadístico multivariante. McGraw-Hill Interamericana.

García, E., \& Mendoza, J. (2015). La confianza en el contexto de los equipos de trabajo virtuales. Innovaciones de negocios, 12(23), $75-95$.

García-Villaverde, P. M., Parra-Requena, G., \& Molina-Morales, F. X. (2018). Structural social capital and knowledge acquisition: implications of cluster membership. Entrepreneurship \& Regional Development, 30(5-6), 530-561.

Germain, M.-L., \& McGuire, D. (2014). The Role of Swift Trust in Virtual Teams and Implications for Human Resource Development. Advances in Developing Human Resources, 16(3), 356-370. 
Gibson, C. B., Huang, L., Kirkman, B. L., \& Shapiro, D. L. (2014). Where global and virtual meet: The value of examining the intersection of these elements in twenty-first-century teams. Annual Review of Organizational Psychology and Organizational Behavior, 1(1), 217-244.

Gilson, L. L., Maynard, M. T., Jones Young, N. C., Vartiainen, M., \& Hakonen, M. (2015). Virtual Teams Research. Journal of Management, 41(5), 1313-1337.

Huang, J. (2016). The Challenge of Multicultural Management in Global Projects. Procedia - Social and Behavioral Sciences, 226, $75-81$.

Huey, S. J., Tilley, J. L., Jones, E. O., \& Smith, C. A. (2014). The contribution of cultural competence to evidence-based care for ethnically diverse populations. Annual Review of Clinical Psychology, 10(1), 305-338.

Kanaris, M. E. (2015). Performances of Trust among Learners in the Context of Online Social Learning (Doctoral dissertation, University of Missouri--Columbia).

Kaplan, D. (2004). The SAGE Handbook of Quantitative Methodology for the Social Sciences.

Kaur, A. (2018). App Review: Trello. Journal of Hospital Librarianship, 18 (1), 95-101.

Kirkman, B. L., \& Mathieu, J. E. (2005). The dimensions and antecedents of team virtuality. Journal of Management, 31(5), 700718.

Lam, C. (2016). Improving technical communication group projects. Journal of Business and Technical Communication, 30(1), 85112.

Lanzas, A. (2018). Modelo de generación de valor mediante el capital intelectual en empresas de base tecnológica de software. Contaduría y Administración, 65.

Marlow, S. L., Lacerenza, C. N., \& Salas, E. (2017). Communication in virtual teams: a conceptual framework and research agenda. Human Resource Management Review, 27(4), 575-589.

Martins, L. L., Gilson, L. L., \& Maynard, M. T. (2004). Virtual teams: What do we know and where do we go from Here? Journal of Management, 30(6), 805-835.

Maznevski, M. L., \& Chudoba, K. M. (2000). Bridging Space Over Time: Global Virtual Team Dynamics and Effectiveness. Organization Science, 11(5), 473-492

Mirra, N., Morrell, E., \& Filipiak, D. (2018). From digital consumption to digital invention: Toward a new critical theory and practice of multiliteracies. Theory Into Practice, 57(1), 12-19.

Orhan, M. (2014). Extending the individual level of virtuality: Implications of task virtuality in virtual and traditional settings. Administrative Sciences, 4(4), 400-412.

Oviedo, H. C., \& Arias, A. C. (2005). Aproximación al uso del coeficiente alfa de Cronbach. Revista Colombiana de Psiquiatría, 34(4), 572-580.

Pasher, E., \& Ronen, T. (2011). The Complete Guide to Knowledge Management.

Powell, A., Picoli, G., \& Ives, B. (2004). Virtual teams. ACMS SIGMIS Database, 35(1), 6-36.

Ramos Rosales, E. C. R., Verduzco Ramírez, J. A., García Díaz, N. y Arceo Díaz, S. (2019). Diseño e implementación de un sistema integral de control de turnos. 3C Empresa. Investigación y pensamiento crítico, 8(1), 92-111.

Rezazadeh, H., \& Molaei, H. (2018). The relationship between the degree of organization's virtualization and the organizational ability. Management Science Letters, 8(6), 619-630.

Rosales, E. C. R. R., Ramírez, J. A. V., Díaz, N. G., \& Díaz, S. A. (2019). Diseño e implementación de un sistema integral de control de turnos. 3c Empresa: investigación y pensamiento critico, 8(1), 92-111.

Rositas, J. (2014). Los tamaños de las muestras en encuestas de las ciencias sociales y su repercusión en la generación del conocimiento. Innovaciones de Negocios, 11(22), 235-268.

Rusman, E., van Bruggen, J., Sloep, P., Valcke, M., \& Koper, R. (2012). Can I trust you? International Journal of Information Technology Project Management, 3(1), 15-35.

Son, S., \& Kim, D.-Y. (2015). The role of perceived feedback sources' learning-goal orientation on feedback acceptance and employees' creativity. Journal of Leadership \& Organizational Studies, 23(1), 82-95.

Steelman, L. A., Levy, P. E., \& Snell, A. F. (2004). The Feedback Environment Scale: Construct Definition, Measurement, and Validation. Educational and Psychological Measurement, 64(1), 165-184.

Takahashi, M., Nemoto, K., Hayashi, N., \& Horita, R. (2014). The measurement of dialogue: From a case study of the workshop using world café as a collective dialogue Method. Journal of Information Processing, 22(1), 88-95.

Tarakci, M., Ateş, N. Y., Floyd, S. W., Ahn, Y., \& Wooldridge, B. (2018). Performance feedback and middle managers' divergent strategic behavior: The roles of social comparisons and organizational identification. Strategic Management Journal, 39(4), $1139-1162$.

Tongco, M. D. C. (2007). Purposive sampling as a tool for informant selection. Ethnobotany Research and Applications, 5 , 147.

Vegh, J., \& Nguyen Luu, L. A. (2019). Intercultural competence developmental models - Theory and practice through comparative analysis. People: International Journal of Social Sciences, 4(3), 882-901.

Zornoza, A., Orengo, V., \& Peñarroja, V. (2009). Relational capital in virtual teams: the role played by trust. Social Science Information, 48(2), 257-281.

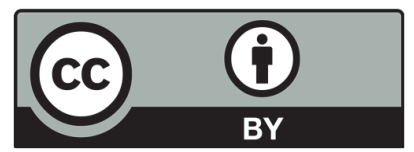

(C) 2020 by the authors; licensee Growing Science, Canada. This is an open access article distributed under the terms and conditions of the Creative Commons Attribution (CC-BY) license (http://creativecommons.org/licenses/by/4.0/). 